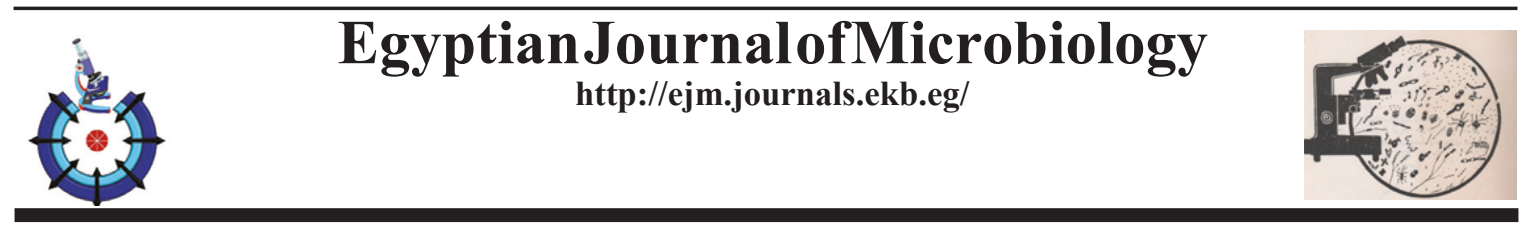

\title{
Detection of Mycobiota and Aflatoxigenic Fungi in Wheat Flour from Markets in Qena City, Egypt
}

\author{
A.A. El-Shahir \\ Botany and Microbiology Department, Faculty of Science, South Valley University, \\ Qena, Egypt.
}

\begin{abstract}
THIRTY wheat flour samples were collected from different bakeries and markets in Qena City, Egypt over five months were used to measure moisture content, fungi and aflatoxins. Moisture contents ranged from $5.92 \%$ to $14.43 \%$. Twenty-one fungal species belonging to 13 genera were isolated from the wheat flour samples on Czapeks agar media at $28^{\circ} \mathrm{C}$. The most common fungal genera were Aspergillus, Mucor and Penicillium. The correlation coefficient analysis revealed to strong positive correlation between moisture content and average total count of fungi in wheat flour samples (0.92). Qualitative and quantitative determination of aflatoxins in 29 isolates of the A. flavi group (A. flavus, A. flavus var. columnaris and A. parasiticus) were made using thin layer chromatography (TLC) and high performance liquid chromatography (HPLC), respectively. The results for (TLC) were as follow: Fourteen isolates (48.2\%) had the ability to produce aflatoxin B1, five isolates (17.2\%) could produce both aflatoxin B1 and aflatoxin B2 and ten (34.4\%) isolates were negative. By using HPLC, the concentrations of aflatoxin were 13.416-9229.343, 2.639-152.668 and 6.391-79.507 $\mu \mathrm{g} / \mathrm{L}$ for AFB1, AFB2, and AFG2, respectively.
\end{abstract}

Keywords: Aflatoxin, Aspergillus flavus, HPLC, TLC, Wheat flour.

\section{Introduction}

Aflatoxins, are mycotoxins that are highly oxygenated poly substituted coumarins. A minimum of 18 various kinds of AFs have been chemically described. They are divided according to fluorescent colors under UV light. Aflatoxins which give strong blue fluorescence are B-aflatoxins, while those that fluoresce yellowgreen on thin-layer chromatography plates are G-aflatoxins (Omara et al., 2020). Aspergilli comprise a group of fungi, but mainly two species, $A$. flavus and $A$. parasiticus, produce aflatoxins. Aflatoxins cannot be broken down by heat during the processing of agricultural commodities. Aflatoxins have harmful effect on humans and animals (carcinogenic, mutagenic, and teratogenic) and this makes them the most widely discussed fungal toxins (Akinola et al., 2019). Till now, the Acceptable Daily Intake (ADI) is not established for aflatoxins, but as genotoxic and carcinogenic substances, ingestion through food should be kept at a minimum level. For protection of consumers from this risk, various countries have established different limits for the AFs in wheat and many wheat products, ranging from $4 \mu \mathrm{g} / \mathrm{kg}$ in the European Union to $30 \mu \mathrm{g} / \mathrm{kg}$ in India (Trombete et al., 2014). Wheat is considered a very compatible substrate for many phytopathogenic and saprophytic microorganisms. Cereal products exemplify a major food resource for the world's population. Different microbial contaminants can grow on end products, especially under unsuitable storage conditions. As a result of higher incidence of major mycotoxigenic fungi in flour, the product became more sensitive to accumulation of mycotoxins (Abo Dahab et al., 2016). Flour has low water activity so it is considered as a microbiologically safe end product, but shelf life and proliferation of spoilage microorganisms depend on moisture (ICMSF, 1998). When the water content exceeds the critical level for wheat 
flour (13\%-15\%) molds start growing (Hassane et al., 2017).

This study aimed to detect mold occurrence, distribution and the aflatoxigenic fungi in samples of wheat flour, intended for human consumption, marketed in Qena, Egypt. The detection of aflatoxin concentrations in Aspergillus flavus group by thin layer chromatography (TLC) and the most advanced techniques of high performance liquid chromatographic (HPLC) analysis were employed in this study. This was done in order to ascertain the safety of wheat flour for human consumption.

\section{Materials and Methods}

\section{Gathering wheat flour samples}

Wheat flour (thirty samples) were collected from bakeries and markets in Qena City, Egypt over five months.

\section{Determination of moisture content}

The following method was used for estimation of moisture content of wheat flour according Association of Official Analytical Chemists (AOAC, 2007). Ten grams of the collected wheat flour (W1) was put into Petri dish, reweighed (W2), and that was then placed in a preset oven at $105^{\circ} \mathrm{C}$ and permitted to stand for $3 \mathrm{hrs}$. Dried samples were put in a desiccator for cooling and these symbolized W3. This procedure was reduplicated until we had a fixed weight. Then a calculations of moisture content was done by the following Equation 1:

$\%$ Moisture Content $=\mathrm{W} 2-\mathrm{W} 3 / \mathrm{W} 1 \times 100 \quad$ Eq. 1

Correlation coefficient was estimated between moisture content and average total count of fungi in each samples of wheat flour.

\section{Mycobiota analysis}

This was made by using "Dilution-Plate Method" for the quantitative determination of fungi as described by Moubasher et al. (1972). For isolation and purification of fungi Czapek's agar medium was used at $28^{\circ} \mathrm{C}$.

\section{Aflatoxins production ability}

Twenty-nine isolates of Aspergillus flavus (A. flavus Link, A. parasiticus and A. flavus var. columnaris) identified from the samples were screened for aflatoxins production.

\section{Thin layer chromatography (TLC) assay}

Yeast extract sucrose agar (YES) was utilized for growing of Aspergillus flavus isolates grown for 7 days at $28^{\circ} \mathrm{C}$ and tested for aflatoxins by TLC analysis as described by Samson et al. (2002) with some amendments. Agar plugs were made by cutting the fungal colony to a diameter of $5 \mathrm{~mm}$. The agar plugs were put in $2 \mathrm{~mL}$ of chloroform for extraction of AFs. The extracts $(10 \mu \mathrm{L})$ were dotted on TLC plates. Also, $10 \mu \mathrm{L}$ of mycotoxin standard solution of aflatoxins B1 and B2 (Sigma-Aldrich, Dorset, UK) were applied as reference standards and dotted along with the fungal samples extract. The plates were put in a solvent tank with in chloroform: toluene: acetone (75:15:10) for $1 \mathrm{hr}$. and visualized under long wave UV light (365nm). Sample extracts were compared to reference standards spots.

High performance liquid chromatography (HPLC) analysis of aflatoxins

Twenty nine isolates of $A$. flavi group isolated from wheat flour were cultivated on Czapek's liquid medium refer to Samson et al. (2002) with some modification. Fifty $\mathrm{mL}$ of the liquid medium were added in each $250 \mathrm{~mL}$ sterile Erlenmeyer flasks. After sterilization each flask was inoculated with 3 agar discs made from 7-day old cultures on YES agar plates. The flasks were then incubated at $28^{\circ} \mathrm{C}$ for 10 days. At the end of incubation period each flask containing Aspergillus culture was extracted with $100 \mathrm{~mL}$ chloroform for $24 \mathrm{hrs}$. at $20^{\circ} \mathrm{C}$ with shaking at (160rpm). The chloroform extract was dried over anhydrous sodium sulphate, filtered and distilled to near dryness. The residue was diluted with chloroform to $1 \mathrm{~mL}$. Agilent Technologies 1200 Series, G1321A FLD HPLC system was used for running the extracts of aflatoxin samples. The system had a Zorbax Eclipse Plus C18 Analytical $4.6 \times 250 \mathrm{~mm} 5$-Micron column. Separation was performed at fixed temperature of $30^{\circ} \mathrm{C}$. About $30 \mu \mathrm{L}$ of each prepared sample was injected in three replicates. Separation was achieved using water $55 \%$, methanol $15 \%$ and acetonitrile $30 \%$ as an isocratic mobile phase at a flow rate of $1.5 \mathrm{~mL} / \mathrm{min}$. Each run was stopped after $15 \mathrm{~min}$. A Diode Array detector was used and fluorescence was recorded at $365 \mathrm{~nm}$ (excitation) and $455 \mathrm{~nm}$ (emission). The resulting chromatograms were tested peak by peak and the peaks that showed lamda max ( $\chi$ max) values within the expected values for aflatoxins were processed by determination of peak areas and peak heights. The values of peak areas and peak heights are directly related to concentration of aflatoxin. 


\section{Results and Discussion}

Mycobiota of wheat flour

Twenty-one fungal species belong to 13 genera were isolated from 29 wheat flour samples on Czapeks agar media at $28^{\circ} \mathrm{C}$. The most common fungal genera were Aspergillus, Mucor and Penicillium. From the above genera, the most prevalent species were A. flavus, A. niger, A. parasiticus and Mucor circinelloids (Table 1). No fungal contamination was recorded in two wheat flour (16 and 26) samples with moisture content $6.8 \%$ and $5.92 \%$, respectively. These results are in partial concordance with those published by several researchers in different places of the world. In Egypt (from five governorates) Rezazadeh et al.
(2013) isolated Aspergillus (A. niger, A. fumigatus, A. flavus, A. glaucus, A. triticum), Acremonium, Alternaria, Fusarium, Mucor, Penicillium and Cladosporium spp. from 89 flour samples. Abo Dahab et al. (2016) found that Aspergillus flavus was the most prevalent fungal species in thirty samples of wheat flour. Also, they isolated $A$. niger, A. tamarii, A. clavatus, A. nidulans, Penicillium spp., Mucor spp., Fusarium spp., Alternaria spp., Rhizopus stolonifer, Cladosporium cladosporioides and yeasts. Okafor \& Eni (2018) isolated Aspergillus flavus and it was the prevalent (31\%) aflatoxigenic fungus isolated from wheat flour in Oja-Ota market compared to A. niger (21\%). Rhizopus sp., Geotrichium sp., Yeast, Penicillium sp. and Paecilomyces sp. were also isolated.

TABLE 1. Average total counts of fungal genera and species recorded in wheat flour on Czapeks agar medium at $28^{\circ} \mathrm{C}$

\begin{tabular}{|c|c|c|c|c|}
\hline Genera \& species & ATC & $\%$ & NCI & OR \\
\hline Acremonium strictum & 73.6 & 3.2 & 3 & $\mathrm{~L}$ \\
\hline Alternaria alternata & 60.3 & 2.6 & 3 & $\mathrm{~L}$ \\
\hline Aspergillus & 1356.9 & 58.2 & 28 & $\mathrm{H}$ \\
\hline A. candidus & 113.9 & 4.9 & 1 & $\mathrm{R}$ \\
\hline A. flavus & 648.9 & 27.8 & 22 & $\mathrm{H}$ \\
\hline A. flavus var.columnaris & 39.8 & 1.7 & 4 & $\mathrm{~L}$ \\
\hline A. fumigatus & 39.8 & 1.7 & 4 & $\mathrm{~L}$ \\
\hline A. niger & 340.9 & 14.6 & 15 & M \\
\hline A. parasiticus & 166.9 & 7.2 & 8 & M \\
\hline A. sydowii & 6.7 & 0.3 & 1 & $\mathrm{R}$ \\
\hline Candida sp. & 87.1 & 3.7 & 2 & $\mathrm{R}$ \\
\hline Drechslera indica & 60.3 & 2.6 & 3 & $\mathrm{~L}$ \\
\hline Emericella nidulans & 53.6 & 2.3 & 4 & $\mathrm{~L}$ \\
\hline Fusarium oxysporum & 46.9 & 2 & 3 & $\mathrm{~L}$ \\
\hline Mucor circinelloids & 166.9 & 7.2 & 9 & M \\
\hline Nectria haematococcum & 20.1 & 0.9 & 3 & $\mathrm{~L}$ \\
\hline Penicillium & 354.1 & 15.2 & 9 & M \\
\hline P. chrysogenum & 59.9 & 2.6 & 3 & $\mathrm{~L}$ \\
\hline P. corylophilum & 247.5 & 10.6 & 5 & $\mathrm{~L}$ \\
\hline P. duclauxi & 46.7 & 2 & 4 & $\mathrm{~L}$ \\
\hline Phoma euprena & 20.1 & 0.9 & 3 & $\mathrm{~L}$ \\
\hline Rhizopus stolonifer & 26.8 & 1.1 & 2 & $\mathrm{R}$ \\
\hline Stachybotrys parvispora & 6.7 & 0.3 & 1 & $\mathrm{R}$ \\
\hline Gross total count & \multicolumn{4}{|c|}{2333.4} \\
\hline Number of genera & \multicolumn{4}{|c|}{13} \\
\hline Number of species & \multicolumn{4}{|c|}{21} \\
\hline
\end{tabular}

$\mathrm{ATC}=$ Average total counts (Calculated per $\mathrm{g}$ of wheat flour), $\mathrm{NCI}=$ Number of cases of isolation (out of 30), $\mathrm{OR}=$ Occurrence remarks $(\mathrm{H}=$ High occurrence, from 16 to 30 cases, $\mathrm{M}=$ Moderate occurrence; from 7 to 15 cases, $\mathrm{L}=$ Low occurrence; from 3 to 6 cases, $\mathrm{R}=$ Rare occurrence; 1,2 cases). 


\section{Moisture content}

The mean of moisture contents of thirty wheat flour samples ranged between 5.92\% and 14.43\%. The correlation coefficient analysis revealed to strong positive correlation between moisture content and average total count of fungi in wheat flour samples (0.92) (Table 2).Al-Defiery \& Mergan (2015) were concluded that increasing moisture content in wheat flour might result in increasing molds, the high total mold counting were developed when percent of moisture was $14.17 \%$. The correlation coefficient analysis revealed to positive correlation between moisture content and molds present (0.73). Moisture is an important factor in flour that has great effects on shelf life and growth of microbes (ICMSF, 1998). $1 \%$ or $2 \%$ change in dry flour moisture contents has been shown to be appropriate for microbial growth and toxin contamination (Eyles et al., 1989) In thirty wheat flour samples gathered from five governorates within three months (Abo Dahab et al., 2016) moisture contents ranged from $9.31 \%$ to $12.4 \%$.

TABLE 2. Correlation coefficient of moisture content with average total count of fungi in wheat flour samples

\begin{tabular}{|c|c|c|c|}
\hline Sample & Average total count of fungi (for each sample) & Moisture content \% & $\begin{array}{r}\text { Correlation } \\
\text { coefficient }\end{array}$ \\
\hline 1 & 140.3 & 11.04 & \multirow{30}{*}{0.92} \\
\hline 2 & 46.8 & 9.38 & \\
\hline 3 & 86.6 & 9.178 & \\
\hline 4 & 60.1 & 9.61 & \\
\hline 5 & 40 & 9.258 & \\
\hline 6 & 33.3 & 8.8 & \\
\hline 7 & 100.5 & 10.72 & \\
\hline 8 & 86.9 & 9.84 & \\
\hline 9 & 174 & 11.52 & \\
\hline 10 & 120.4 & 10.24 & \\
\hline 11 & 241 & 14.43 & \\
\hline 12 & 46.9 & 8.99 & \\
\hline 13 & 174.2 & 12.82 & \\
\hline 14 & 214.2 & 14.22 & \\
\hline 15 & 33.1 & 7.87 & \\
\hline 16 & 0 & 6.8 & \\
\hline 17 & 100.5 & 9.01 & \\
\hline 18 & 40.2 & 8.69 & \\
\hline 19 & 107 & 11.77 & \\
\hline 20 & 19.9 & 6.8 & \\
\hline 21 & 26.6 & 8.81 & \\
\hline 22 & 60 & 7.89 & \\
\hline 23 & 33.3 & 7.95 & \\
\hline 24 & 166.9 & 12.58 & \\
\hline 25 & 93.6 & 8.98 & \\
\hline 26 & 0 & 5.92 & \\
\hline 27 & 13.2 & 6.87 & \\
\hline 28 & 13.2 & 9 & \\
\hline 29 & 60.2 & 7.88 & \\
\hline 30 & 26.4 & 9.3 & \\
\hline
\end{tabular}

*Pearson's correlation coefficient is a linear correlation coefficient that returns a value of between -1 means strong negative correlation and +1 means strong positive correlation. A 0 means no correlation (zero correlation). 
Thin layer chromatograph (TLC) assay

Twenty nine isolates of A. flavus, A. parasiticus and A. flavus var. columnaris were identified and subjected to qualitative assays for aflatoxin production by TLC assay. Results revealed that fourteen isolates $(48.2 \%)$ had the ability to produce Aflatoxin B1, five isolates (17.2\%) could produce both Aflatoxin B1 and Aflatoxin B2 and ten $(34.4 \%)$ isolates are negative as shown in (Table 3 and Fig. 1).

TABLE 3. TLC analysis of aflatoxins in cultural resumes of A. flavus, Aspergillus flavus var. columnaris. and $A$. parasiticus strains

\begin{tabular}{|c|c|c|}
\hline Strain code & $B_{1}$ level & $B_{2}$ level \\
\hline WH-AF1 & - & - \\
\hline WH-AF2 & - & - \\
\hline WH-AP3 & + & + \\
\hline WH-AC4 & ++ & - \\
\hline WH-AF5 & + & - \\
\hline WH-AF6 & + & - \\
\hline WH-AF7 & - & - \\
\hline WH-AF8 & - & - \\
\hline WH-AP9 & ++ & - \\
\hline WH-AF10 & - & - \\
\hline WH-AF11 & ++ & - \\
\hline WH-AP12 & + & - \\
\hline WH-AF13 & - & - \\
\hline WH-AF14 & ++ & - \\
\hline WH-AP15 & +++ & +++ \\
\hline WH-AP16 & ++++ & ++++ \\
\hline WH-AF17 & + & - \\
\hline WH-AF18 & ++++ & ++++ \\
\hline WH-AC19 & + & - \\
\hline WH-AP20 & - & - \\
\hline WH-AF21 & ++ & - \\
\hline WH-AP22 & + & - \\
\hline WH-AF23 & + & - \\
\hline WH-AP24 & +++++ & +++++ \\
\hline WH-AF25 & ++++ & ++++ \\
\hline WH-AF26 & - & - \\
\hline WH-AC27 & ++ & - \\
\hline WH-AC28 & - & - \\
\hline WH-AF29 & - & - \\
\hline
\end{tabular}

$\mathrm{WH}=$ Wheat flour, $\mathrm{AF}=$ Aspergillus flavus Link, $\mathrm{AP}=$ Aspergillus parasiticus and $\mathrm{AC}=$ Aspergillus flavus var. columnaris.

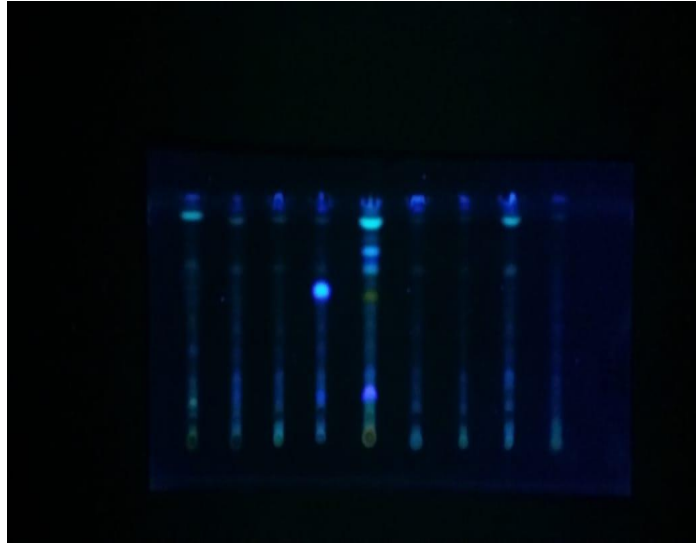

Fig. 1. Detection of aflatoxin production in Aspergilli isolates from wheat flour using thin-layer chromatography [Starting from left, isolate WH-AF21 to isolate WH-AF29 on the right]

Thin layer chromatography (TLC) as an analytical method has been used in detection of aflatoxin (Stroka \& Anklam, 2000). TLC is the oldest, and simplest chromatographic technique, demanding less advanced devices (Whitaker et al., 1996). Atanda et al. (2005) reported that aflatoxigenic isolates show blue or blue green fluorescence at long wave UV. Abo Dahab et al. (2016) revealed that two isolates extracts were TLC positive out of thirty isolates isolated from wheat flour. Also results here are similar to results of (Saleem \& Al-Johani, 2018) who showed that in regard to different types of aflatoxins, aflatoxin B1 is usually common and is the most toxic compound was predominant and was found in 14 samples $(58.3 \%)$ out of 24 cultural extracts of $A$. flavus and A. parasiticus analyzed on TLC plates. Akinola et al. (2019) isolated Aspergillus sp. from wheat flour from supermarkets in Mafikeng, North West Province, South Africa. TLC detection was done for Aspergillus isolates. Nineteen (42\%) out of 45 strains were aflatoxigenic.

\section{High performance liquid chromatography} (HPLC) analysis of aflatoxins

Direct toxicity and long term carcinogenic effect of Aspergillus are associated with certain metabolites such as aflatoxins made by the genus Aspergillus. Grains and grain products proved to be a good substance for aflatoxin producing fungi. Thus, it was urgent to detect any toxic compounds made by the A. flavus isolates isolated from the contaminated grain and grain products (wheat flour, bread, ...etc.). Using, HPLC technique, it was found that $A$. flavi culture extracts showed 
variable levels of aflatoxins and exhibited peaks similar to those for aflatoxin standard (Figs. 2, 3, 4 and 5). Out of 29 isolates 26 isolates $(89.6 \%)$ were positive for at least one aflatoxin. The range of aflatoxins concentrations were 13.4169229.343, 2.639-152.668 and 6.391-79.507 $\mu \mathrm{g} /$ $\mathrm{L}$ for aflatoxins B1, B2, and G2, respectively (Table 4). Similar results were reported by ElShanshoury et al. (2014) who screened 33 isolates of A. flavus for AF production. Results showed that 26 isolates produced AFB1, AFB2, AFG1). Each isolate of $A$. flavus has a diversity in type of toxin and quantities. The percentage of AFB1, AFB2 and AFG1 of A. flavus Link isolates, were $78 \%, 71 \%$, and $36 \%$ of the isolates. Hassan \& ElSayed (2015) who collected different isolates of Aspergillus flavus and A. parasiticus from 500 different cereal samples from different markets in Sharkia, Egypt for quantification of aflatoxins by HPLC method. They found that $60 \%$ of total isolates had the ability for producing aflatoxin $\mathrm{B}_{1}$ in average amount 4.9-200ng/ $\mu \mathrm{L}$. Segura et al. (2020) detected and quantified aflatoxin B1 from Aspergillus flavus obtained from peanut samples gathered at various retail markets in the region of Ribeirão Preto, São Paulo, Brazil, by HPLC/ UV-DAD. They confirmed that 7 fungi samples were aflatoxigenic. Aflatoxin B1 levels averaged from 4 to $285 \mu \mathrm{g} / \mathrm{mL}$. Also, Alshannaq \& Hyuk Yu (2020) who used HPLC with fluorescence (FLD) detectors to determine the presence and amounts of aflatoxin (AF) B1, B2, G1, and G2 levels in several fungal isolates of $A$. flavus, A. oryzae and A. parasiticus. The limit of quantification (LOQ) for AFs was 0.025 to $2.5 \mathrm{ng} / \mathrm{mL}$ with FLD.

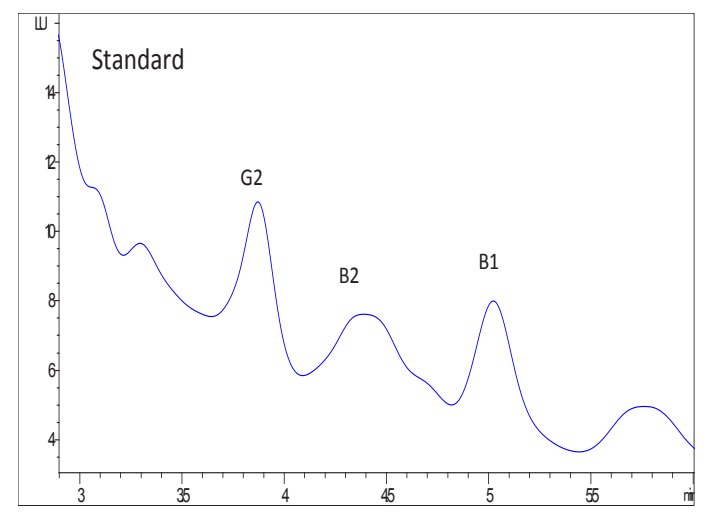

Fig. 2. Chromatograms obtained for a mixed aflatoxin standard (AFB1, AFB2 and AFG2) [Vertical axes represents wave length (u) and horizontal axes represents time in minutes ( $\min )]$

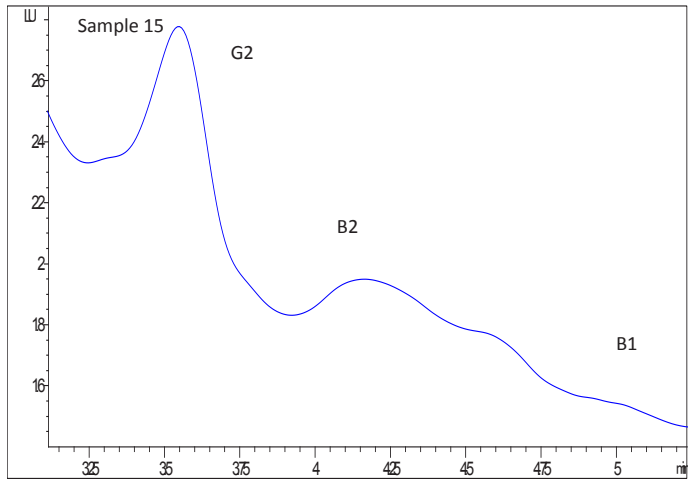

Fig. 3. HPLC analysis of aflatoxins in cultural extract of Aspergillus parasiticus isolated from wheat flour (strain 15 ) [Vertical axes represents wave length (u) and horizontal axes represents time in minutes (min)]

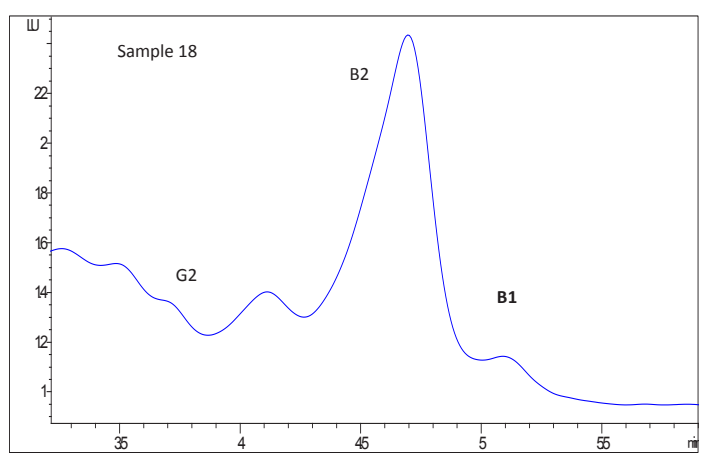

Fig. 4. HPLC analysis of aflatoxins in cultural extract of Aspergillus flavus isolated from wheat flour (strain 18) [Vertical axes represents wave length (u) and horizontal axes represents time in minutes (min)]

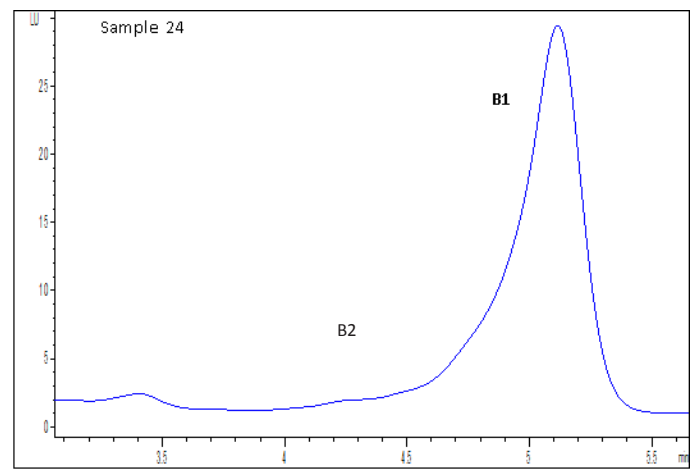

Fig. 5. HPLC analysis of aflatoxins in cultural extract of Aspergillus parasiticus isolated from wheat flour (strain 24 ) [Vertical axes represents wave length (u) and horizontal axes represents time in minutes $(\mathrm{min})]$ 
TABLE 4. Aflatoxins concentrations in different $A$. flavi group cultural extracts by HPLC analysis (Aflatoxins concentrations $\mu \mathrm{g} / \mathrm{L})$

\begin{tabular}{|c|c|c|c|}
\hline Strain code & $\mathrm{B}_{1}$ & $\mathrm{~B}_{2}$ & $\mathrm{G}_{2}$ \\
\hline WH-AF1 & - & - & - \\
\hline WH-AF2 & 15.980 & - & - \\
\hline WH-AP3 & - & 2.639 & 8.683 \\
\hline WH-AC4 & - & 14.054 & 14.150 \\
\hline WH-AF5 & 13.416 & - & 6.391 \\
\hline WH-AF6 & - & 6.025 & 18.298 \\
\hline WH-AF7 & - & - & - \\
\hline WH-AF8 & 14.987 & - & - \\
\hline WH-AP9 & 17.446 & - & 14.029 \\
\hline WH-AF10 & 15.999 & - & - \\
\hline WH-AF11 & - & 10.885 & 14.134 \\
\hline WH-AP12 & - & 7.797 & 20.816 \\
\hline WH-AF13 & - & - & - \\
\hline WH-AF14 & 13.675 & 5.817 & 21.677 \\
\hline WH-AP15 & 16.296 & 17.525 & 79.507 \\
\hline WH-AP16 & 55.076 & 9.547 & 15.428 \\
\hline WH-AF17 & 16.867 & 5.748 & 13.238 \\
\hline WH-AF18 & 24.543 & 152.668 & 8.082 \\
\hline WH-AC19 & 21.450 & 2.211 & 11.032 \\
\hline WH-AP20 & - & - & 10.061 \\
\hline WH-AF21 & - & 16.903 & 12.159 \\
\hline WH-AP22 & - & 8.863 & 7.208 \\
\hline WH-AF23 & - & 5.705 & 16.706 \\
\hline WH-AP24 & 9229.343 & 5.671 & - \\
\hline WH-AF25 & - & 10.766 & 6.773 \\
\hline WH-AF26 & -- & - & 8.098 \\
\hline WH-AC27 & 14.753 & 6.281 & 13.614 \\
\hline WH-AC28 & 15.043 & - & - \\
\hline WH-AF29 & 14.990 & - & - \\
\hline
\end{tabular}

$\mathrm{WH}=$ Wheat flour, $\mathrm{AF}=$ Aspergillus flavus Link, $\mathrm{AP}=$ Aspergillus parasiticus and $\mathrm{AC}=$ Aspergillus flavus var. columnaris .

Numerous studies have been made lately to control aflatoxins, but many are not yet advanced at the commercial scale. Further research is suggested on new technologies for the control of AFs with the main object of protecting human and animal food/feed safety. The best way to control mycotoxin contamination is preventing mycotoxin production at farm level. Obstruction of aflatoxins or minimize their content in foodstuffs could be done by various methods (Chemical, biological and physical methods). Applications in molecular techniques and other detoxification methods like gamma irradiation and microwave heating were effective in this field. Bacillus subtilis and Bacillus lichenformis could be used for detoxification of aflatoxins. All these detoxification methods discussed in details by Zhu et al. (2016), Udomkun et al. (2017), Ismail et al. (2018), Luo et al. (2018), Peng et al. (2018), Nazhand et al. (2020).

\section{Conclusion}

I collected 30 wheat flour samples from different bakeries and markets in Qena City, Egypt over five months. In order to make detection of moisture content, fungi and aflatoxins. Moisture contents ranged from $5.92 \%$ and $14.43 \%$. The 
correlation coefficient analysis revealed to strong positive correlation between moisture content and average total count of fungi in wheat flour samples. Twenty-one fungal species belong to 13 genera were isolated from 30 wheat flour samples on Czapeks agar media at $28^{\circ} \mathrm{C}$. The most common fungal genera were Aspergillus, Mucor, Penicillium. Qualitative and quantitative determination of aflatoxins in 29 isolates of $A$. flavi group (A. flavus, A. flavus var. columnaris and $A$. parasiticus) were used by thin layer chromatography TLC and High performance liquid chromatographic (HPLC), respectively. The results in (TLC) were as follow fourteen isolates $(48.2 \%)$ had the ability to produce aflatoxin B1, five isolates $(17.2 \%)$ could produce both aflatoxin B1 and aflatoxin B2 and ten (34.4\%) isolates are negative. By using (HPLC) technique the concentrations of aflatoxin were 13.4169229.343, 2.639-152.668 and 6.391-79.507 $\mu \mathrm{g} / \mathrm{L}$ for AFB1, AFB2, and AFG2, respectively.

\section{Recommendation}

Wheat flour is a significant food resource for the world population. Flour quality estimation regarding to mold infestation and mycotoxins contamination is important for producing safe food. The moisture content is a main factor for growth of microorganisms and contamination so it should be less than $5.9 \%$. The correlation coefficient analysis revealed to strong positive correlation between moisture content and average total count of fungi in wheat flour samples Qualitative and quantitative estimation of aflatoxins and aflatoxigenic fungi by TLC and HPLC methods are precise, speedy and less expensive techniques to prove a primary alert of contamination.

Acknowledge: Special thanks and gratitude are offered to all colleauges in Botany \& Microbiology Department, Faculty of Science, South Valley University for their cooperation and support during conducting this study.

\section{Refrences}

Abo Dahab, N.F., Abdel-Hadi, A.M., Abdul-Raouf, U.M., El-Shanawany, A.A., Hassane, A.M.A. (2016) Qualitative detection of aflatoxins and aflatoxigenic fungi in wheat flour from different regions of Egypt. IOSR Journal of Environmental Science, Toxicology and Food Technology, 10(7), 20-26.
Akinola, S.A., Ateba, C.N., Mwanza, M. (2019) Polyphasic assessment of aflatoxin production potential in selected Aspergilli. Article in Toxins, 2019(11), 692. Doi:10.3390/toxins11120692.

Al-Defiery, M.E.J., Merjan, A.F. (2015) Mycoflora of mold contamination in wheat flour and storage wheat flour. Mesopotamia Environmental Journal, 1(2), 18-25.

Alshannaq, A.F., Hyuk, Y.J. (2020) A liquid chromatographic method for rapid and sensitive analysis of aflatoxins in laboratory fungal cultures. Toxin, 12, 93. Doi:10.3390/toxins 12020093.

AOAC (2007) "Official Methods of Analysis", $18^{\text {th }}$ ed.; Association of Official Analytical Chemists, Ed.; AOAC: Washington, DC, USA.

Atanda, I., Rati, E.R., Ozoja, N. (2005) Palm kernel: A potential substrate for rapid detection of aflatoxigenic fungi. Food Sci.Technol. Int. 11(1), 67-74.

El-Shanshoury, A.R., El-Sabbagh, S.M., Emara, H.A., Saba, H.E. (2014) Occurrence of moulds, toxicogenic capability of Aspergillus flavus and levels of aflatoxins in maize, wheat, rice and peanut from marketsin central delta provinces, Egypt. Int J. Curr. Microbiol. App. ScI. 3(3), 852-865.

Eyles, M.J., Moss, R., Hocking, A.D. (1989) The microbiological status of Australian flour and the effects of milling procedures on the microflora of wheat and flour. Food Aust. 41, 704-708.

Hassan, M., El-Sayed, Nada, H.A. (2015) Detection of aflatoxins by HPLC and the expression of biosynthetic nor-1 gene of aflatoxin and ocrA gene of ochratoxin. Benha Veterinary Medical Journal, 29(2), 1-10.

Hassane, A.M.A., El-Shanawany, A.A., Abo-Dahab, N.F., Abdel-Hadi, A.M., Abdul-Raouf, U.M., Mwanza, M. (2017) Influence of different moisture contents and temperature on growth and production of aflatoxin B1 by a toxigenic Aspergillus flavus isolate in wheat flour. J. Ecol. Heal. Environ. 5, $77-83$.

ICMSF (International Commission on Microbiological Specifications for Foods) (1998) Microorganisms in Foods: 6 Microbial Ecology of Food Commodities. Blackie Academic and Professional, London, pp. 
313-346

Ismail, A., Gonçalves, B.L., de Neeff, D.V., Ponzilacqua, B., Coppa, C.F.S.C., Hintzsche, H., Sajid, M., Cruz, A.G., Corassin, C.H., Oliveira, C.A.F. (2018) Aflatoxin in foodstuffs: Occurrence and recent advances in decontamination. Food Res. Int. 113, 74-85.

Luo, Y., Liu, X., Li, J. (2018) Updating techniques on controlling mycotoxins-A review. Food Control, 89, $123-132$.

Moubasher, A.H., El-Naghy, M.A., Abdel-Hafez, S.I.I. (1972) Studies on the fungus flora of three grains in Egypt. Mycopathol. Mycolo. Appl. 47(3), 261-274.

Nazhand, A., Durazzo, A., Lucarini, M., Souto, E.B., Santini, A. (2020) Characteristics, occurrence, detection and detoxification of aflatoxins in foods and feeds. Foods, 9, 644. Doi:10.3390/ foods 9050644 .

Okafor, S.E., Eni, A.O. (2018) Microbial quality and the occurrence of aflatoxins in Plantain/Yam and wheat flours in Ado-Odo Ota. IOP Conference Series: Earth and Environmental Science, 210, 012017

Omara, T., Nassazi, W., Omute, T., Awath, A., Laker, F., Kalukusu, R., Musau, B., Nakabuye, B.V., Kagoya, S., Otim, G., Adupa, E. (2020) Aflatoxins in Uganda: An encyclopedic review of the etiology, epidemiology, detection, quantification, exposure assessment, reduction, and control. International Journal of Microbiology, 2020 |ArticleID 4723612 | 18 pages | https://doi. org/10.1155/2020/4723612.

Peng, Z., Chen, L., Zhu, Y., Huang, Y., Hu, X., Wu, Q., Nüssler, A.K., Liu, L., Yang, W. (2018) Current major degradation methods for aflatoxins: A review. Trends Food. Sci. Tech. 80, 155-166.

Rezazadeh, A., Pirzeh, L., Hosseini, M., Razavieh, S.V. (2013) Evaluation of fungal contaminations and humidity percent of consumed flour in the bakeries of Tabriz city. J. Paramed. Sci. 4, 82-86.

Saleem, A., Al-Johani, M. (2018) Mycobiota and chromatographic analyses of aflatoxin contamination of Aspergillus species isolated from poultry feed. Journal of Food Safety, https://doi. org/10.1111/jfs.12560.

Samson, R., Hoekstra, E., Frisvad, J., Filtenborg, O. (2002) "Introduction to Food Borne Fungi". $6^{\text {th }} \mathrm{ed}$., Cen-traalbureau voor Schimmelcultures, Utrecht, The Nether-lands.

Segura, G.G., Arevabini, C.A.M., Heinzen de Abreu, M., Bitencourt, T.A., Nishimura, F.G., Beleboni, R., Marins, M., Fachin, A.L. (2020) The molecular and analytical methods reveal aflatoxin B1producing Aspergillus flavus isolated from ready to eat peanut samples are resistant to the antifungal agent methyl-thiophanate. Journal of Food Science \& Technology, 5(1), 1-7.

Stroka, J., Anklam, E. (2000) Development of a simplified densitometer for the determination of aflatoxins by thin-layer chromatography. $J$. Chromatogr. A., 904(2), 263-268.

Trombete, M., Moraes. D.A., Porto, Y.D., Santos, T.B., Direito, G.M., Fraga, M.E., Saldanha, T. (2014) Determination of aflatoxins in wheat and wheat by-products intended for human consumption, marketed in Rio de Janeiro, Brazil. Journal of Food and Nutrition Research, 2(10), 671. DOI:10.12691/ jfnr-2-10-3.

Udomkun, P., Wiredu, A.N., Nagle, M., Muller, J., Vanlauwe, B., Bandyopadhyay, R. (2017) Innovative technologies to manage aflatoxins in foods and feeds and the profitability of application-A review. Food Control, 76, 127-138.

Whitaker, T., Horwitz, W., Albert, R., Nesheim, S. (1996) Variability associated with analytical methods used to measure aflatoxin in agricultural commodities. J. AOAC Int. 79, 476-485.

Zhu, Y., Hassan, Y., Watts, C., Zhou, T. (2016) Innovative technologies for the mitigation of mycotoxins in animal feed and ingredients-A Review of Recent Patents. Anim. Feed Sci. Techn. 216. DOI: $10.1016 /$ j.anifeedsci.2016.03.030 


\section{الكثف عن العدد الكلي للفطريات و الفطريات المنتجة لسموم الافلاتوكسين في دقيق القمح من أسواق مدينة قنا، مصر \\ أماني عطا الثهير \\ قسم النبات و الميكروبيولوجي ـ كلية العلوم - جامعة جنوب الو ادي ـ قنا ـ مصر.}

تم تقدير العدد الكلي للفطريات المصاحبة للاقيق و الفطريات المنتجة للافلاتوكسين في ثلاثثين عينة من دقيق القمح

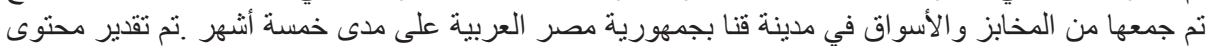

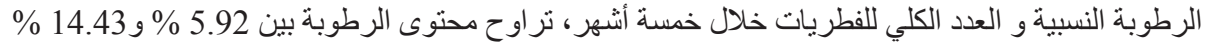

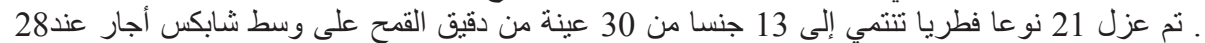

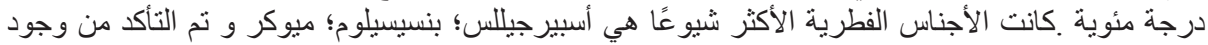

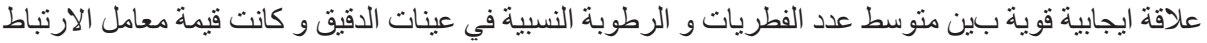

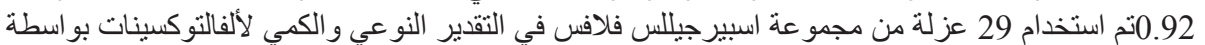
كانت النتائج في HPLC وTLC كما يلي أربعة عشر عزلة 2.

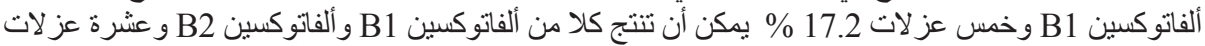

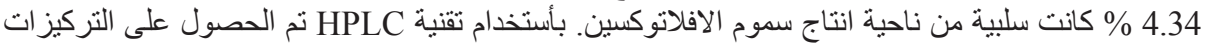

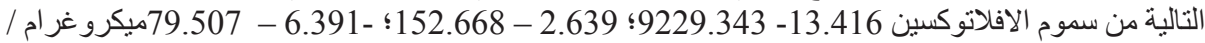
لتر لألفالتوكسين B1 و B2 و G2 على G2 التى التو الي. 